\title{
Contribuições da saúde do trabalhador à educação infantil: o sofrimento mental de educadoras de uma creche paulistana
}

\author{
Renata Paparelli, Thaís Aurungo José, \\ Luna Gonçalves da Silva e Tânia Corghi Veríssimo \\ Pontifícia Universidade Católica de São Paulo
}

\begin{abstract}
A pesquisa-intervenção, iniciada como estágio supervisionado, desenvolveu-se durante o ano de 2006. Partiu-se da constatação do aumento do número de auxiliares de desenvolvimento infantil de creches conveniadas à Prefeitura Municipal de São Paulo que recorrem ao Centro de Referência em Saúde do Trabalhador e ao Sindicato da categoria nos últimos anos com queixas que se referem especialmente à incidência de sofrimento psíquico relacionado ao trabalho. Buscou-se contribuir com as trabalhadoras de uma das creches conveniadas na investigação das causas do sofrimento mental que têm vivenciado, além de colaborar com a construção de formas de enfrentamento transformadoras dessa realidade, constituídas coletivamente e a partir da articulação entre o conhecimento prático (saber-fazer das trabalhadoras) e o conhecimento teórico (aquele que trazemos de nossa inserção na universidade). Para tanto, foram realizados encontros periódicos com as trabalhadoras na creche, observações do cotidiano de trabalho, reuniões com a equipe dirigente da instituição e devolutivas a todas as participantes. $O$ trabalho revelou a presença de intenso sofrimento psíquico relacionado ao trabalho e de vivências de humilhação, tudo isso adquirindo novas feições na atual política pública voltada à Educação Infantil no Brasil.
\end{abstract}

Palavras-chave: Saúde do trabalhador, Saúde do trabalhador da educação, Trabalho penoso, Sofrimento mental no trabalho, Creches, Educação infantil.

Contributions from workers' health to the child education: workers' psychological suffering in a day-care center in the city of São Paulo

This intervention-research, which started during a period of supervised training, was developed during the year of 2006. It began with the observation of the increasing number of complaints by child development assistants from day-care centers associated to the city of São Paulo who have been turning to the reference center for workers' health as well as to their trade union with grievances regarding psychological suffering related to work. This research aimed not only to contribute with the women workers of one of the associated day-care centers in the inquiry of the causes of this mental suffering they have gone through but also to collaborate with the construction of transforming forms of confronting such reality by the collectively produced connection between practical knowledge (the workers' know-how) and theoretical knowledge (the one we bring because of our insertion in the university) of the involved sides. For that, periodic meetings with the workers in the day-care center, observation of their daily routine, meetings with the leading team of the institution were carried out and then fed back to all the participants. The work disclosed the presence of intense psychological suffering and humiliation experiences related to their work, features recently acquired in the current public policy directed to Child Education in Brazil.

Keywords: Health of the worker, Health of the worker of education, Laborious work, Mental suffering at the work, Day-care centers, Child education.

presentaremos a seguir um trabalho de pesquisa-intervenção realizado com Auxiliares
de Desenvolvimento Infantil (ADI's) de uma creche, conveniada à Prefeitura
Municipal de São Paulo, localizada na periferia leste da cidade, trabalho informado pela
perspectiva da Saúde do Trabalhador ${ }^{1}$. O trabalho caracterizou-se inicialmente como
atividade de estágio curricular supervisionado, vinculado ao Núcleo de Psicologia
Organizacional e do Trabalho do quarto ano do curso de Psicologia da PUC-SP, ao Centro de
Referência em Saúde do Trabalhador da Mooca (CRST-Mooca) e ao Sindicato da categoria,

1 Perspectiva que será explicitada adiante. 
o Sitraemfa (Sindicato dos Trabalhadores em Entidades de Assistência e Educação à Criança, ao Adolescente e à Família do Estado de São Paulo). Depois do primeiro semestre de estágio obrigatório, a equipe continuou o trabalho por mais um semestre, tendo durado o processo, ao todo, um ano $(2006)^{2}$.

A elaboração do projeto deu-se a partir de uma constatação preocupante: o aumento progressivo do número de ADI's de creches conveniadas à prefeitura que recorrem ao CRSTMooca nos últimos anos, aumento que também tem acontecido na procura pelo Sindicato. As queixas referem-se especialmente à incidência de sofrimento psíquico relacionado ao trabalho. Com a pesquisa, pretendemos investigar as causas do sofrimento mental vivenciado pelas trabalhadoras de uma dessas creches conveniadas, localizada na área de abrangência do CRST-Mooca. Procuramos também contribuir para a construção de formas de enfrentamento transformadoras dessa realidade, constituídas coletivamente e a partir da articulação entre o conhecimento prático (saber-fazer das trabalhadoras) e o conhecimento teórico (aquele que trazemos de nossa inserção na universidade).

\section{A Educação Infantil no Brasil}

Apresentaremos aqui uma breve contextualização da Educação Infantil no Brasil, com o intuito de trazer elementos para uma melhor compreensão do drama vivido pelas ADI's $^{3}$ no seu cotidiano de trabalho. Assim, apontaremos definições e aspectos históricos, focalizando o momento de transição pelo qual passa a modalidade de ensino em questão, no qual destacaremos as ambigüidades e imprecisões da política educacional no que se refere às exigências de formação das profissionais de Educação Infantil.

\section{Histórico e definições}

Segundo Rosemberg, Campos e Pinto (1985), as creches surgiram e ganharam espaço no Brasil em meio a movimentos populares como a "Luta por creches" (1979), respondendo às necessidades de uma realidade marcada pela emancipação feminina e pela entrada das mulheres no mercado de trabalho. O Estado respondeu às reivindicações feitas pelos movimentos destinando vagas para a população de baixa renda, tendo as creches assumido, desde o início, um caráter assistencialista e paternalista bastante presente até hoje na Educação Infantil, modalidade de ensino marcada por dificuldades financeiras, falta de assistência técnica, falta de treinamento e de preparação dos profissionais.

A rede de atenção à Educação Infantil no Brasil traz as marcas de uma história dúplice: segundo Campos, Rosemberg e Ferreira (1995),

(...) pode-se considerar que, na faixa de 0 a 6 anos de idade, consolidaram-se dois tipos de atendimento paralelos: o que se convencionou chamar de creche, de cunho mais assistencial e de cuidado, e a pré-escola, ligada ao sistema educacional e refletindo suas prioridades de caráter instrucional (p. 104).

\footnotetext{
2 Estagiárias: Thaís Aurungo José, Luna Gonçalves da Silva e Tânia Corghi Veríssimo. Supervisora do estágio na PUC-SP: Renata Paparelli. Supervisora do estágio no CRST-Mooca: Elizabeth Nogueira.

3 Sempre que nos referirmos a Auxiliares de Desenvolvimento Infantil o faremos no feminino, em respeito ao fato de que essa atividade é majoritariamente (se não exclusivamente) realizada por mulheres.
} 
$\mathrm{O}$ atendimento destinado às crianças de zero a três anos (as creches) e aquele oferecido às crianças de quatro a seis (a pré-escola) são marcados até hoje por essas diferenças historicamente construídas, como aponta análise da Unesco (2003):

no Brasil, o atendimento a faixa etária de zero a três anos cresceu à margem do sistema educacional em programas alternativos, informais. Em geral, esses programas vinculamse ao setor da Assistência Social, funcionam em espaços comunitários ou domésticos, não exigem qualificação profissional e são ofertados a uma população vulnerabilizada que não tem acesso às creches (p. 27).

À duplicidade no atendimento às crianças (cuidar versus educar), historicamente construída, articulam-se as dificuldades de delimitação das faixas etárias a serem atendidas e a grande diversidade de instituições incumbidas da Educação Infantil. Vejamos o caso paulistano.

Centro de Educação Infantil (CEI) é a nomenclatura atual para as creches, nomenclatura que expressa a vontade de que as creches possam assumir também a tarefa educativa, superando o caráter eminentemente "cuidador". Entretanto, os próprios dados oficiais da Secretaria Municipal de Educação (SME) revelam que as duas nomenclaturas continuam em uso, já que ora apresentam as instituições de atendimento à infância como "CEI's", ora nomeiam essas mesmas instituições como "creches". A distribuição das faixas etárias também revela certa confusão instalada na rede de atendimento: as Escolas Municipais de Educação Infantil (EMEI's) atendem apenas crianças de quatro a seis anos; em tese, os CEI's deveriam matricular apenas crianças de zero a três anos; mas, na realidade, os CEI's acabam aceitando crianças com até seis anos. Além dos CEI's e das EMEI's, tem-se também os CEU's (Centros Educacionais Unificados), que atendem à população infantil, incluindo creche e Escola de Educação Infantil, além de Escola de Ensino Fundamental e outros equipamentos de cultura e lazer ${ }^{4}$.

Além da divisão anteriormente apresentada, as creches vinculadas à Prefeitura Municipal de São Paulo podem ser de três tipos: creches diretas, indiretas e conveniadas (Rosemberg, Campos \& Pinto, 1985). As creches diretas são aquelas que pertencem à estrutura da Rede Municipal de Ensino, contam com o trabalho de servidores públicos e com o suporte oferecido às outras escolas da rede. As indiretas caracterizam-se como entidades privadas sem fins lucrativos nas quais o equipamento pertence ao poder público, que participa de sua conservação e garante o seu funcionamento através de auxílio financeiro e assistência técnica. As creches conveniadas, também privadas e sem fins lucrativos, são aquelas em que a entidade providencia o prédio, o mobiliário e o equipamento e o poder público participa do funcionamento, através de auxílio financeiro e assistência técnica. Nessas últimas, o suporte financeiro oferecido refere-se ao pagamento dos profissionais que atuam na creche, indexado ao número de crianças ali atendidas (per capita).

As conveniadas sempre assumiram uma dimensão importante na rede de Educação Infantil. Dados do ano de 2000 (Crepaldi, 2002, p. 129) revelam essa importância no quadro de instituições de ensino do Município de São Paulo, que contava naquele ano com 370 conveniadas , 270 unidades diretas e 140 unidades indiretas.

\section{Período de transição na Educação Infantil}

Podemos dizer que as creches/CEI's vivem um período de transição, tendo em vista mudanças na legislação, as quais expressam transformações de concepção do que seja infância e decorrem da luta por qualidade de ensino na Educação Infantil. Destacam-se,

4 Passaremos a designar o CEI como "creche/CEI” para mantermos presente a realidade contraditória de sua configuração atual. 
nesse sentido: a busca pela construção de uma rede de Educação Infantil integrada, com definições claras acerca dos distintos papéis de cada um de seus elementos, as faixas etárias correspondentes, as formas de avaliação da qualidade do ensino oferecido etc.; a transformação da ênfase no "cuidar" em ênfase no "educar", o que implica em alterações profundas no dia-a-dia das instituições e nos lugares institucionais ocupados pelos diversos profissionais de ensino; a problematização do nível de qualificação formal das ADI's das creches/CEI's e a busca por parâmetros que possam nortear a formação a ser exigida.

A Constituição de 1988 traz um salto qualitativo na concepção de criança e, conseqüentemente, no conceito de creche/CEI, referindo-se, pela primeira vez na história brasileira, a direitos específicos das crianças, superando as expressões de mero cuidado, como "amparar" ou "assistir" e incluindo um novo elemento, a educação (Campos, Rosemberg \& Ferreira, 1995). A agregação desse novo elemento pode ser considerada um passo importante para a superação da visão assistencialista predominante na história da formação das creches/ CEI's, sendo que a subordinação do atendimento em creches/CEI's e pré-escolas à área da educação (passando da Secretaria de Assistência Social à Secretaria da Educação) deve ser considerada uma iniciativa que integra esses esforços. Rosemberg, Campos e Pinto (1985) definem e sintetizam o papel que as instituições de Educação Infantil passam a assumir - pelo menos formalmente - a partir de 1988, voltado à priorização do tema educação:

[creche e pré-escola dizem respeito a] toda instituição especializada onde a família deixa seus filhos de 0 a 6 anos, em regime semi-internado, levando e trazendo a criança para a casa todos os dias. A creche deve oferecer serviços que incluem os cuidados físicos com a criança - alimentação, higiene, saúde -, cuidados ligados à sua afetividade e socialização e os referentes ao seu desenvolvimento motor e cognitivo (p. 4).

A discussão sobre a qualidade da Educação Infantil vem adquirindo maior espaço a partir da década de 90. Foi nesse período, em 1996, que ocorreu a aprovação da Lei de Diretrizes e Bases da Educação (LDB), que revela as mesmas preocupações que a Constituição de 1988 quanto ao acesso à educação para as crianças freqüentadoras de creches/CEI's, que municipaliza a responsabilidade pela Educação Infantil e enfatiza a questão da qualificação das trabalhadoras de creches/CEI's.

Essa formação das profissionais das creches/CEI's, entretanto, aparece na LDB com ambigüidades, dando margem a leituras que vão desde a dispensa de exigência de nível superior para as ADI's, até a afirmação dessa exigência e de prazos para que seja cumprida. É nesse sentido que o diagnóstico efetivado pela Unesco (2003) sobre a Educação Infantil no Brasil afirma:

o aspecto mais complexo, entretanto, relaciona-se a um profissional geralmente denominado assistente, auxiliar ou monitor. Algumas regulamentações municipais prevêem esse profissional com formação de ensino fundamental, o que é objeto de discordância de especialistas da área, para quem não se admitiria profissional nãoqualificado em nível médio atuando diretamente com as crianças (p. 27).

A própria denominação do profissional de creche/CEI é polêmica, conforme trabalho organizado por Rossetti-Ferreira, Mello, Vitória et al. (2005):

(...) uma das discussões e especulações diz respeito à denominação do profissional de creche: professor, auxiliar de ensino, educador ou agente de educação? Essa discussão não é supérflua como pode parecer. É muito diferente se aquela pessoa que fica com a criança é um professor ou um agente de educação. Ao agente educacional não é previsto o mesmo nível de formação pedido ao professor. Diferenças na capacitação pressupõem diferenças na vida do profissional: no salário, nas condições de trabalho, nos direitos e deveres etc. (p. 187). 
Acrescenta-se a esse problema a indefinição quanto à natureza e à responsabilidade pelo financiamento dessa formação:

finalmente, do ponto de vista da organização de uma política de formação de profissionais para a educação, há pontos centrais que não estão sendo discutidos e aos quais tão pouco a legislação parece estar atenta. Até o momento, não houve nenhuma manifestação do MEC e mesmo das Secretarias de Educação no sentido de alocar recursos para a formação de profissionais para o setor. Segundo tendências recentes, é provável que será a ação individual dos agentes educativos que gerará mudanças no perfil de qualificação do quadro profissional que atua no setor (Nascimento, 2001, p. 110).

Além dos aspectos anteriormente mencionados, cabe apontar que a exigência de qualificação trouxe implicações diferentes para as profissionais de creches/CEI's ou de préescolas, pois, enquanto já se exigia das professoras de pré-escola a formação em curso de magistério, para as profissionais das creches/CEI's não havia a necessidade de formação específica relacionada à Educação Infantil. Essa recente mudança na legislação do país representa grande desafio para as educadoras das creches/CEI's, especialmente as das conveniadas e das indiretas, pois tais profissionais, ao que tudo indica e de acordo com o verificado na pesquisa de campo por nós empreendida, praticamente não contam com o apoio da Secretaria Municipal de Educação, estando à mercê de baixos salários, dupla rotina de cuidado da família e das crianças que freqüentam a creche e a conseqüente falta de tempo, energia e recursos financeiros.

O quadro traz preocupações também quando consideramos que o baixo nível de instrução das educadoras é generalizado no Brasil: no ano de 2003, 64\% das funções docentes na pré-escola contavam com profissionais de nível médio e $23 \%$ com profissionais de nível superior. Já nas creches/CEI's, embora as estatísticas do MEC não abranjam todos os estabelecimentos, temos indicadores de deficiências de formação mais graves (Campos, Fullgraf \& Wiggers, 2006).

O portal do MEC divulgou recentemente um diagnóstico do nível de formação das profissionais que atuam na Educação Infantil. A tabela abaixo sistematiza esse diagnóstico:

\begin{tabular}{|c|c|c|c|c|c|c|c|c|}
\hline \multicolumn{9}{|c|}{ Número de funções docentes por nível de formação e nível/modalidade de atuação em 2004} \\
\hline \multicolumn{8}{|c|}{ Educação Infantil } & \\
\hline \multirow{3}{*}{$\begin{array}{l}\text { Modalidade de } \\
\text { atendimento }\end{array}$} & \multicolumn{2}{|c|}{ Fundamental } & \multicolumn{2}{|l|}{ Médio } & \multicolumn{3}{|l|}{ Superior } & \multirow{3}{*}{$\begin{array}{l}\text { Total } \\
\text { Geral }\end{array}$} \\
\hline & Completo & Incompleto & $\begin{array}{l}\text { Magistério } \\
\text { completo }\end{array}$ & $\begin{array}{l}\text { Outra formação } \\
\text { completa }\end{array}$ & $\begin{array}{l}\text { Licenciatura } \\
\text { completa }\end{array}$ & \multicolumn{2}{|c|}{ Completo com licenciatura } & \\
\hline & & & & & & Com Magistério & Sem Magistério & \\
\hline Creche & 1664 & 3.799 & 44.119 & 7.777 & 14.010 & 3.188 & 718 & 75.275 \\
\hline Pré-escola & 1.551 & 5.426 & 171.112 & 12.684 & 85.775 & 15.046 & 2.104 & 293.698 \\
\hline Total & 3.215 & 9.225 & 215.231 & 20.461 & 99.785 & 18.234 & 2.822 & 368.973 \\
\hline
\end{tabular}

Fonte: INEP/Censo Escolar de 2004.

\section{A pesquisa sobre as Auxiliares de Desenvolvimento Infantil}

Realizamos amplo levantamento bibliográfico sobre o tema da saúde mental de trabalhadores de creches/CEI's nas bibliotecas da USP, através do Dedalus (catálogo online do Banco de Dados Bibliográficos da USP) e nas bibliotecas da PUC-SP, por meio do catálogo on-line do Lumen (Sistema de Bibliotecas da PUC-SP). Além disso, foram 
pesquisados vários sítios considerados relevantes, tais como o portal da Associação Nacional de Pós-graduação e Pesquisa em Educação (ANPEd) e do Ministério da Educação (MEC).

Não encontramos nada diretamente relacionado ao tema em nosso levantamento. Esse dado é confirmado por duas abrangentes pesquisas que analisam o estado da arte dos trabalhos sobre Educação Infantil no Brasil.

A base de dados "O estado do conhecimento da Educação Infantil no Brasil", trabalho realizado por Rocha, Silva Filho e Strenzel (1999), contém 270 dissertações e 19 teses que foram apresentadas nos Programas de Pós-graduação da área entre 1983 e 1996. Além disso, agrega também 143 artigos que foram publicados em oito periódicos nacionais da área da educação, no mesmo período ${ }^{5}$. Totalizam-se 432 registros. Nos descritores aparece o tema "saúde", mas a análise das ocasiões em que esse termo aparece revela que se trata da saúde das crianças, educação em saúde, a escola como promotora de educação em saúde etc., mas não de Saúde do Trabalhador. Não há trabalhos, portanto, que se refiram à penosidade do trabalho das ADI's.

Rocha (1998), buscando tecer o estado da arte das pesquisas em Educação Infantil no Brasil, toma como base de análise a produção científica que vem sendo apresentada nas Reuniões Anuais da Associação Nacional de Pós-graduação e Pesquisa em Educação principalmente nos anos de 1990 a 1996. De forma complementar, foram também incluídos na seleção trabalhos apresentados nesse mesmo período em congressos científicos das ciências sociais, da história, da psicologia e da Sociedade Brasileira para o Progresso da Ciência (SBPC). De uma forma geral, foram selecionadas para análise todas as pesquisas nacionais que se referiam diretamente às instituições de Educação Infantil que pudessem trazer alguma contribuição para a "pedagogia da Educação Infantil". Também nessa pesquisa não foram feitas referências ao trabalho das ADI's na perspectiva de sua saúde, aspecto que consideramos imprescindível para pensar quaisquer questões da Educação Infantil.

\title{
Algumas considerações sobre trabalho e saúde mental
}

\begin{abstract}
O hábito tem-lhe amortecido as quedas. Mas sentindo menos dor, perdeu a vantagem da dor como aviso e sintoma. Hoje em dia vive incomparavelmente mais sereno, porém em grande perigo de vida: pode estar a um passo de estar morrendo, a um passo de já ter morrido, e sem o benefício de seu próprio aviso prévio.
\end{abstract}

Não Sentir, Clarice Lispector.

O trabalho é a atividade planejada e consciente através da qual o Homem produz um mundo para si, construindo-se a si mesmo nesse processo - "si" no sentido humano-genérico, não apenas no sentido individual (Heller, 1972; Marx, 1978). Está intimamente ligado à construção da própria subjetividade. Enquanto atividade humana por excelência, promotora de processos de vida, de complexificação da experiência, de articulação entre pensamento e ação e entre teoria e prática, está relacionado à possibilidade de o Homem ocupar o lugar de sujeito no processo produtivo. Sabemos que a forma hegemônica assumida pelo trabalho no modo capitalista de produção - o trabalho alienado - não possibilita essa condição, dividindo

\footnotetext{
5 Tratam-se dos seguintes periódicos: Cadernos de Pesquisa, da Fundação Carlos Chagas; Revista da ANDE, da Associação Nacional de Educação; Série Idéias, da Fundação para o Desenvolvimento em Educação (FDE); Cadernos CEDES, do Centro de Estudos Educação e Sociedade; Revista Educação \& Sociedade, do Centro de Estudos Educação e Sociedade; Revista Perspectiva, do CED/UFSC; Cadernos do CED, da UFSC; Revista Pró-Posições da Faculdade de Educação da UNICAMP, que passou a ser publicada a partir de 1990.
} 
os seres humanos entre os que pensam e os que realizam, os que planejam e os que executam, os que mandam e os que obedecem, os que realizam suas atividades para atender suas necessidades e interesses privados e aqueles que trabalham vendendo sua força de trabalho no mercado. Sabemos, também, que o trabalho educativo não escapa totalmente dessa lógica, apesar de guardar especificidades ${ }^{6}$.

De qualquer modo, o fato de ser mais ou menos sujeito no processo de produção está diretamente relacionado às possibilidades de o trabalho inserir-se no processo de saúde ou no de adoecimento. A saúde é caracterizada tradicionalmente como um estado de bem-estar biopsicossocial, estado de ausência de doenças. Quando essa concepção é confrontada com o fato de que as características essenciais do humano são o movimento, a diversidade e não a estabilidade, abre-se o campo para o questionamento dessa perspectiva e de sua superação (Dejours, 1986). Saúde é um processo e não um estado, sendo que o mais importante nesse processo é o Homem ali comparecer como sujeito, como alguém com condições e instrumentos para interferir naquilo que lhe causa sofrimento. Essa perspectiva considera os indivíduos em sua diversidade (somos diferentes uns dos outros) e variabilidade (somos variáveis com relação a nós mesmos conforme os diversos momentos pelos quais passamos no decorrer de nossa existência). Depreende-se disso que o trabalho alienado, aquele no qual o Homem não comparece como sujeito, é penoso, ou seja, produz sofrimento mental. E que existem vários graus de penosidade nas organizações do trabalho.

A perspectiva da Saúde do Trabalhador trouxe muitos avanços enquanto modelo explicativo da relação entre saúde e trabalho, permitindo o desvelamento da complexidade dos agravos à saúde nos tempos modernos, inclusive do sofrimento mental no trabalho (Mendes \& Dias, 1991). Em contraposição às formas anteriormente produzidas de investigação dessa relação, na Saúde do Trabalhador o conceito-chave para se compreender o adoecimento psíquico no trabalho é o de organização do trabalho (Sato, 1995). A organização do trabalho é expressão da divisão social do trabalho no modo capitalista de produção, representa a divisão do poder (divisão entre quem pensa e quem executa, quem manda e quem só deve obedecer) e é essa divisão que, por sua vez, define fundamentalmente as condições de trabalho às quais os trabalhadores são submetidos.

Quanto menos o trabalhador puder intervir sobre o que lhe causa sofrimento, quanto mais inflexível for a organização do trabalho, menos ele terá condições de respeitar o seus limites subjetivos (quanto, quando e como suporta as demandas do trabalho) e mais penosa será a realização da atividade.

Como essas categorias que definem a penosidade no trabalho estão presentes na atividade das ADI's?

\section{A pesquisa-intervenção na creche/CEI}

O trabalho na creche/CEI teve a duração de um ano. Contou com diversos tipos de atividades: observação do cotidiano de trabalho na instituição; reuniões com a equipe dirigente (coordenadora e diretora); reuniões inicialmente semanais e posteriormente quinzenais com as ADI's, com duração aproximada de uma hora; encontros devolutivos com todas as participantes. Além disso, a equipe inteira reuniu-se semanalmente para análise e discussão do processo.

O principal objetivo da pesquisa-intervenção foi o de conhecer a realidade do trabalho das ADI's, entender o porquê da grande procura de atendimento no CRST-Mooca 
por essas profissionais, compreender, enfim, o impacto subjetivo da atividade tal como se constitui na organização do trabalho tecida pelas regras do convênio com a prefeitura e pelas especificidades da instituição em questão. Conhecer para buscar construir, junto com as trabalhadoras, formas de enfrentamento coletivas dos problemas encontrados?

Objetivos específicos: a) propiciar um espaço de reflexão e não-cotidianeidade (Heller, 1972) que promovesse o encontro entre as trabalhadoras e o debate acerca de seu trabalho; b) conhecer a visão das trabalhadoras sobre o trabalho que realizam, seus limites e possibilidades, especialmente no que se refere à relação entre saúde e trabalho; c) entender quais são os principais problemas que atravessam suas atividades, bem como as formas de enfrentamento adotadas.

As reuniões do grupo ocorreram no horário de almoço das profissionais, segundo elas, o único momento possível devido à dinâmica do trabalho. Assim, no primeiro semestre foram realizados quatro encontros com as ADI's divididas em dois subgrupos de cinco cada, para que pudessem se organizar em um "rodízio" (enquanto cinco participavam do grupo, as outras cinco cuidavam das crianças). No segundo semestre, com o grupo de dez ADI's, foram realizados sete encontros mais duas reuniões para devolutivas. No quarto encontro do segundo semestre, fatores como cansaço e falta de tempo para a resolução de assuntos pessoais (ir ao banco, correio etc.) - normalmente resolvidos no horário de almoço começaram a pesar e, por conta disso, algumas ADI's solicitaram uma diminuição da freqüência das reuniões, que passaram a ocorrer quinzenalmente.

Os grupos foram conduzidos pelas três estagiárias, que assumiram funções diferentes e não rigidamente estabelecidas para a condução do trabalho: uma coordenadora, que direcionava as atividades do grupo, buscando proporcionar a todas um espaço de fala e interlocução; uma co-coordenadora, responsável por colaborar com a coordenação na condução do grupo; e uma observadora cuja tarefa principal era a de registrar as falas e outras manifestações do grupo ${ }^{8}$.

O registro das falas, que apresentava dados de cada um dos encontros (temática, articulação entre os diversos conteúdos apresentados, as transformações no pensamento das ADI's, o movimento do grupo), foi objeto de análise semanal da equipe. O material obtido a partir dos grupos de discussão foi devidamente organizado conforme categorias estabelecidas a partir do próprio material disponível. Realizou-se uma análise de conteúdo (Bardin, 1977; Minayo, 1993) em conformidade com essas mesmas categorias, sempre tendo em vista responder às perguntas colocadas de acordo com as diversas concepções dos depoentes.

\section{A instituição e as trabalhadoras}

A creche/CEI na qual foi realizado o trabalho é conveniada à Prefeitura Municipal de São Paulo, atendendo, desde 1987, crianças na faixa etária de um a quarto anos, em regime de período integral, das 7 h30 às 17 h30 horas. Está localizada em um bairro da Zona Leste de São Paulo, submetida à Coordenadoria Regional de Ensino da Penha, coordenadoria responsável por 29 Centros de Educação Infantil (CEI) conveniados, 33 CEI's diretos, 15 CEI indiretos e 46 EMEI's (dados do sítio da SME, 2006).

Em seu início, contava com quatro funcionários e atendia quinze crianças. Viveu nos vinte anos de sua história uma significativa ampliação: após um ano da inauguração, a creche/CEI conveniou-se com a Prefeitura Municipal de São Paulo para subsidiar o aumento do número de crianças usuárias para setenta. Ao final da intervenção (dezembro de 2006),

7 Nesse sentido, o trabalho realizou-se de modo similar ao de Jardim, Otero, Silva e Dowbor (2004).

8 Essa configuração da equipe de coordenação tem sido utilizada em diversas intervenções em Saúde do Trabalhador, como por exemplo Bernardi, Queiroz, Lima et al. (2000). 
trabalhavam ali dezessete pessoas (diretora, coordenadora pedagógica, auxiliar de enfermagem, cozinheira, auxiliar de cozinha, duas faxineiras e dez educadoras) e eram atendidas cento e vinte crianças.

As crianças estão divididas em cinco salas, sendo um berçário (um a dois anos), dois mini-grupos (de dois a três anos) e dois maternais (três a quarto anos). O financiamento pela prefeitura dá-se de modo per capita, ou seja, a atribuição de verba faz-se em função do número de crianças atendidas. Segundo a diretora da instituição, o financiamento dado pela prefeitura cobre apenas $70 \%$ do orçamento da creche, sendo os outros $30 \%$ preenchidos com doações.

As dez ADI's da creche/CEI apresentam-se como um grupo relativamente homogêneo. São mulheres, em sua maioria jovens de 20 a 30 anos (a mais nova tem 20 e mais velha, 60 anos), mães, com baixa escolaridade e moradoras de bairros periféricos, muitas necessitando de mais de uma condução para se locomover ao trabalho e gastando muito tempo no trajeto até a creche/CEI. Trabalham no local há bastante tempo, sendo que a maioria atua na creche há mais de dez anos e chegou a esse trabalho por indicação de alguma colega que já atuava na instituição anteriormente, sendo que algumas são membros da mesma família. A maioria tem uma jornada dupla de trabalho, já que são mães de filhos pequenos e, ao chegarem em casa, além de realizar os afazeres domésticos, cuidam de suas próprias crianças. O grau de instrução formal é baixo: no geral, as ADI's não possuem formação no ensino médio e algumas delas não concluíram o ensino fundamental.

\section{Resultados}

Veio o que era a última coisa do mundo que eu esperava de mim: a docilidade. Uma docilidade de besta de carga resignada. Parecia que eu tinha nascido para esperar, para receber, para executar ordens - que nunca tinha feito senão isso -, que nunca mais faria outra coisa. Não tenho orgulho em confessar isso. É a espécie de sofrimento de que nenhum operário fala; dói demais, só de pensar.

Carta a Albertine Thévenon 1934-1935, Simone Weil.

O ambiente de trabalho das ADI's caracteriza-se pela precariedade e pela improvisação na adaptação do espaço como creche. Embora seja um local bem iluminado, alegre, com pássaros, peixes e fotografias das crianças na entrada, é bastante fechado, com grades e trancas nas portas e janelas. O espaço da creche/CEI é amplo e repartido por divisórias que não conseguem isolar o barulho das salas de aulas, o que torna o ambiente bastante ruidoso. Além disso, as salas são pequenas em função da quantidade de crianças distribuídas em cada uma delas (em média, vinte e cinco crianças por sala). A creche/CEI conta também com lugares destinados ao teatro, quadra de esportes e um parquinho.

A sobrecarga de trabalho das ADI's é bastante evidente, tendo-se em vista o alto número de crianças pelo qual cada uma é responsável (duas profissionais para cada grupo de vinte e cinco crianças, em média) associado à prática corrente do desvio de função, conforme relatam as próprias trabalhadoras: "a gente faz de tudo um pouco, faxina, limpa, lava, cozinha, além de cuidar das crianças". Em conseqüência do esgotamento resultante da sobrecarga de trabalho e das condições em que é realizado, muitas revelam a vontade de desligar-se da instituição, dizendo que só não o fazem porque preferem ser demitidas para receber a multa por rescisão contratual. 
As principais queixas de adoecimento referidas giram em torno de dores na coluna, nas articulações, nos membros superiores, nos inferiores e na cabeça (queixas que representam fortes indícios de LER/DORT), além de acometimento freqüente de viroses, dores de garganta, rouquidão e perda da voz. Esses sintomas, por sua vez, provavelmente decorrem de carregamento de peso excessivo, posturas inadequadas, exposição constante a ruído e uso excessivo da voz, que tem que competir com o ambiente barulhento. As queixas referem-se também ao sofrimento mental, fenômeno que, de tão presente no dia-a-dia, acabou ganhando nomeação própria: as trabalhadoras criaram termos como "agonia na cabeça" e "nervos à flor da pele" como forma de expressar a penosidade do trabalho, o constante desrespeito do seu limite subjetivo. Algumas falas:

A gente enfrenta agora [a equipe dirigente] porque chegou o meu limite.

Muitas vezes a mente também fica doente, você mesma percebe, fica sensível, quando está mal, dá uma agonia na cabeça, e quando dá isso, fico na cozinha, me isolo.

O sofrimento mental decorrente do trabalho ultrapassa os muros da creche/CEI, repercutindo de modo direto na vida pessoal das ADI's, que levam seu esgotamento para outros espaços, como a própria casa onde são chamadas de "estressadas". Um exemplo disso é a reclamação das famílias dessas trabalhadoras em relação ao seu vício em usar um alto tom de voz devido ao excesso de ruído no trabalho. Também não conseguem dedicar carinho e cuidados aos seus próprios filhos:

Tenho paciência e controle sobre vinte crianças e não consigo com o meu filho...

Aqui na creche eu tenho paciência, mas em casa não!

A penosidade do trabalho das ADI's está relacionada a diversas questões. Destacaremos algumas delas, tendo em vista sua importância: a exigência de formação para as profissionais, sem possibilidades concretas de efetivação; a rígida hierarquia presente no sistema educacional, que opera uma divisão do trabalho na qual as ADI's estão postas como meras executoras de regras definidas em outros lugares; a desvalorização de seu conhecimento prático, que se acentua nesse contexto de transição pelo qual passam as creches/CEI's hoje.

$\mathrm{Na}$ creche/CEI pesquisada havia um consenso de que as ADI's deviam se formar em pedagogia ou magistério nos próximos três anos (o ano-limite era 2009), dado que era compartilhado com o sindicato da categoria e que parecia se apoiar nas contradições e nas ambigüidades da própria $\mathrm{LDB}$ nos tópicos em que se refere ao assunto.

Essa exigência atua como um verdadeiro "fantasma", que amedronta as trabalhadoras, as quais, sem apoio nem da creche/CEI, nem da prefeitura, vêem-se diante da impossibilidade de voltar aos bancos escolares. Essa exigência também age no interior da instituição como fator que reitera e intensifica a desvalorização do conhecimento prático, do saber-fazer das ADI's, já que é tomada como legitimadora apenas do conhecimento teóricotécnico, daquele que elas não possuem.

É desse modo que a avaliação que fazem de si vem sempre marcada pela desqualificação e desvalorização devido à sua baixa escolaridade, "elas pensam que a gente não sabe fazer nada além disso", "acham que somos burras". Embora afirmem categoricamente que "não se trocam por quem tem duas faculdades", que "deviam valorizar o nosso trabalho porque a gente está no dia-a-dia com a criança", e valorizem qualidades como a ética, honestidade, o respeito ao outro, resgatando o seu saber-fazer diário com as crianças, também demonstram insegurança em relação à capacidade de corresponder às expectativas da equipe dirigente e às exigências da lei, tal como compreendidas por elas: "para continuar empregada, deverá ser educadora, caso contrário, não há nada que possa fazer aqui". Temos aqui um discurso ambíguo, 
que afirma e nega, ao mesmo tempo, o valor do saber-fazer dessas trabalhadoras. Discurso ambíguo que, longe de expressar falta de clareza de raciocínio, revela o modo como essa ambigüidade está presente na realidade. Nas palavras de Chaui (1996):

ora, seres e objetos culturais nunca são dados, são postos por práticas sociais e históricas determinadas, por formas de sociabilidade, da relação inter-subjetiva, grupal, de classe, da relação com o visível e o invisível, com o tempo e o espaço, com o possível e o impossível, com o necessário e o contingente. Para que algo seja isto ou aquilo e isto e aquilo é preciso que seja assim posto ou constituído pelas práticas sociais (...) Ambigüidade não é falha, defeito, carência de um sentido que seria rigoroso se fosse unívoco. Ambigüidade é a forma de existência dos objetos da percepção e da cultura, percepção e cultura sendo, elas também, ambíguas, constituídas não de elementos ou de partes separáveis, mas de dimensões simultâneas (p. 122, grifos da autora).

Esse período de transição (da atividade caracterizada de modo pejorativo como de "cuidadoras" para a valorizada atividade de "educadoras") parece intensificar e fazer reviver marcas profundamente negativas na identidade das profissionais, marcas de quem tem reiterado no dia-a-dia de trabalho um lugar de subordinação e de humilhação social (Gonçalves Filho, 1998). Ao mesmo tempo, essa transição enfraquece o sentido grande que o trabalho com crianças tem para essas mulheres, sentido esse muito presente em suas falas:

Trabalhar com criança é muito bom, tem que fazer o que a gente gosta. O cansaço é por causa dos adultos e não das crianças.

Outro aspecto importante relacionado aos efeitos do período de transição é a falta de clareza sobre a delimitação de suas novas atribuições como educadoras, tendo os processos de mudança promovido apenas uma idéia difusa sobre o que é ser educadora infantil (quais suas funções, sua importância no processo educacional da criança etc.). As trabalhadoras, colocadas que são no lugar de não-saber, sem a possibilidade de intervenção e discussão sobre o próprio trabalho, acabam por assumir essa mesma condição, compondo uma rotina ocupacional caracterizada pelo trabalho fragmentado. Reduzem sua capacidade a atividades simplificadas e ordenadas em que falta uma ligação com o trabalho mais propriamente educativo, restringindo-se a trabalhos mais de cuidado, o que vai à contramão do que se quer produzir com a própria política educacional.

Coordenação e direção também se sentem pressionadas para que as ADI's realizem o "curso superior", sendo bastante cobradas pela Secretaria da Educação. Verifica-se aí que a rígida hierarquia presente no interior da creche/CEI não foi gestada apenas ali, que faz parte de uma grande cadeia de avaliação e controle, fiscalização, punição: coordenação e direção pressionam as ADI's, desconsideram suas reais possibilidades de ampliarem a sua formação, ao mesmo tempo em que são punidas pelo fato de as ADI's não estarem cumprindo com essa exigência, sem que seja considerada a impossibilidade da própria equipe dirigente.

A equipe dirigente vive uma espécie de compasso de espera, uma contagem regressiva vinculada à própria sobrevivência da creche/CEI. Vejamos o impasse do ponto de vista da equipe dirigente: as ADI's não se formam porque seriam "acomodadas", não desejariam ascender na carreira; se não se formarem, terão que ser demitidas, caso contrário, a creche/CEI seria descredenciada do convênio com a prefeitura e, desse modo, estaria fadada ao fechamento; não há verba suficiente para operar a demissão das ADI's, a creche/CEI não tem recursos para arcar com as multas do INSS; como, então, arranjar dinheiro para a demissão? De outro lado, a equipe dirigente guarda algum reconhecimento ao trabalho das ADI's, afirmando a dificuldade de serem substituídas, devido a sua prática com as crianças e a um saber-fazer que, embora desvalorizado ("quem iria querer fazer o que elas fazem, limpar criança o dia inteiro?", diz a diretora), seria suficiente para garantir a manutenção do emprego. 
Todo esse processo repõe o desencontro entre ADI's e equipe dirigente, fortalecendo a divisão do trabalho presente na instituição, reforçando as relações rigidamente hierarquizadas presentes na forma como o trabalho é organizado e o lugar que as "desqualificadas" ali ocupam. É assim que a falta de formação das trabalhadoras impediria, segundo direção e coordenação, o diálogo com elas e justificaria o lugar que predominantemente habitam, aquele a partir do qual não teriam contribuições, sugestões ou a possibilidade de transformar a própria atividade. Aqui se verifica um grande ressentimento: algumas ADI's chegaram às lágrimas ao contar episódios de humilhação vividos nessa hierarquia na qual ocupam o lugar de subalternas (nas palavras da diretora, de "serviçais"). Episódios que tinham acontecido há muitos anos e que não eram esquecidos, continuavam presentes, machucando.

O futuro está, para as ADI's, profundamente marcado pelas mazelas vividas no presente. Sentem-se numa contagem regressiva para o desemprego, enfrentando cada dia de trabalho sem saber o que será de si mesmas e de seu trabalho no dia seguinte. Esse futuro está intimamente relacionado a processos de adoecimento, percebem-se fadadas a ele:

Nosso futuro é ser doente, ter dor de coluna.

Seremos velhas e doentes.

O grupo transformou-se bastante durante os encontros. Inicialmente, as ADI's acabavam por atribuir os conflitos vividos no trabalho (não-reconhecimento do seu saberfazer, falta de autonomia etc.) unicamente às figuras que ocupam os cargos dirigentes, entendendo que as práticas autoritárias derivavam exclusivamente de características pessoais de diretora e coordenadora, personalizando os problemas. E como únicas alternativas de enfrentamento, identificavam, naquele momento, apenas o embate individual ou a submissão diante de arbitrariedades da instituição. Aos poucos, foi-se constituindo uma visão mais ampliada do problema, na medida em que discutimos questões referentes à organização do trabalho, à distribuição do poder, à rígida hierarquia, às formas de avaliação e controle implementadas na rede de ensino etc.

Alguns aspectos da posição ocupada pelas trabalhadoras na creche/CEI evidenciaram-se nos nossos encontros, tais como a reprodução da divisão entre quem pensa e quem executa, pois as ADI's, freqüentemente colocadas nesse lugar de não-saber, viam-nos como detentoras das soluções imediatas para os impasses vividos. Ao nos colocar nessa posição, tomavam como natural o lugar de subalternidade a partir do qual não se sentiam capazes de pensar e intervir na realidade, condição de submissão que se estende para suas vidas fora do ambiente de trabalho. Essa divisão foi sendo gradativamente enfrentada nos encontros, na medida em que as convocávamos a pensar e discutir conjuntamente as dificuldades e possibilidades do trabalho.

Quando trouxemos para o grupo questionamentos a respeito do como lidar com as dificuldades do trabalho trazidas por elas, inicialmente colocaram como alternativas situações que em geral contribuiriam para a perpetuação dessa condição de submissão ao que é dado. Podemos dizer que suas reflexões iam mais no sentido da tolerância do que da mudança. Como exemplo, uma das saídas apontadas pelo grupo para o impasse demissão-formação foi a realização de festas e bingos visando à arrecadação de dinheiro para demissão, tendo em vista o fato de a instituição não dispor de recursos suficientes para o pagamento da multa pela rescisão contratual.

O processo de grupo trouxe mudanças significativas na natureza das propostas das trabalhadoras, propiciando a construção de sugestões de transformação ativa da realidade do trabalho, considerando a sua complexidade. Como exemplos dessas propostas, temos:

- conquistar maior consideração do conhecimento prático que possuem; 
- buscar relações mais horizontalizadas no trabalho;

- cada sala deveria ter pelo menos duas ADI's, tal como previsto, mas pouco efetivado, tendo em vista o alto absenteísmo;

- revezamento de serviço;

- existência de no mínimo duas ou três reuniões com os pais por ano;

- diminuição da carga horária de trabalho.

O dispositivo grupal revelou-se, assim, no interior dos limites historicamente postos, um espaço potencialmente promotor de saúde, já que permitiu o encontro entre pessoas que a organização do trabalho divide e isola. Possibilitou a construção de formas de enfrentamento coletivo de problemas coletivamente pensados e contribuiu para a ressignificação do dia-a-dia institucional.

Viabilizou também a construção de uma resposta às perguntas que formulamos inicialmente acerca da penosidade do trabalho das ADI's e de suas causas: a pesquisaintervenção revelou que o trabalho daquelas profissionais é gerador de intenso sofrimento mental, na medida em que estão colocadas em um lugar de assujeitamento e subalternidade, não dispondo de recursos para enfrentar e transformar o que causa sofrimento e incômodo. Ao mesmo tempo em que são retiradas do lugar de sujeitos de seu trabalho, têm sido convocadas a serem "educadoras", ou seja, a realizarem um trabalho que exige que sejam autoras de suas práticas, participantes do processo de construção, implementação e avaliação de suas ações. Tudo isso sem que sejam oferecidas as mínimas condições necessárias para uma formação que valha como alicerce dessas novas condutas.

\section{Considerações finais}

Esta pesquisa-intervenção na área da Saúde do Trabalhador teve como objetivo avaliar a existência de penosidade no trabalho das ADI's de creches/CEI's conveniadas, procurando elucidar o fenômeno do aumento da procura, por parte da categoria, tanto do CRST-Mooca quanto do Sitraemfa, com queixas relacionadas a sofrimento mental no trabalho e colaborar com a construção de formas de enfrentamento transformadoras dessa realidade. Para tanto, empregou método qualitativo de investigação e procedimentos coerentes com essa perspectiva, como os grupos de discussão e a realização de observações e reuniões com a equipe dirigente da creche/CEI pesquisada. Desse modo, buscamos assegurar que os fenômenos aqui analisados, longe de representarem especificidades da instituição em questão, falem de uma realidade maior, de problemas vividos na rede conveniada como um todo.

Constatou-se grande sofrimento psíquico nessa categoria profissional, sendo ele intimamente ligado à maneira como a organização do trabalho está estruturada: de forma rígida e inflexível, sendo as ações planejadas pela equipe dirigente e não por quem as realiza, estando as trabalhadoras colocadas no lugar contraditório de objetos. Trata-se de um trabalho marcado pela escassez de possibilidade de interlocução, por intensa sobrecarga e desgaste. Esse quadro de sofrimento mental no trabalho adquire novas feições diante dos impasses trazidos pelo momento de transição na Educação Infantil no país, com especial ênfase às dificuldades concretas de construção de um novo lugar para as ADI's, que não estão sendo contempladas com possibilidades de ampliação de sua formação e ao mesmo tempo estão sendo pressionadas nesse sentido. 
Após um ano com o grupo, verificamos que suscitamos diversos questionamentos sobre a vivência cotidiana das trabalhadoras. Nesse sentido, contribuímos com o estabelecimento de um espaço antes inexistente na instituição, coisa importante para disparar um processo de transformação.

Também saímos transformadas: durante esse período, ficou evidente a importância das noções de equipe, processo e construção coletiva que o pensar e o fazer em Saúde do Trabalhador exigem. Construção coletiva que procura articular o saber teórico e o saber prático, que toma como fundamental a compreensão dos trabalhadores acerca do trabalho que realizam, acerca de seus limites e possibilidades e do sentido que deve nortear as transformações. Isso é tão mais importante em atividades nas quais se entende que o trabalhador deve ocupar o lugar de protagonista, agente, como a atividade educativa. E talvez essa seja a maior contribuição deste artigo: a afirmação de que não há como pensar em qualidade de ensino sem se considerar as questões que atravessam o trabalho dos trabalhadores da Educação, ou seja, sem se considerar o campo da Saúde do Trabalhador e suas contribuições. É nesse mesmo sentido que avaliamos a importância da publicação deste artigo, que busca fazer ecoar o sofrimento ainda pouco explorado desta categoria.

\section{Referências}

Bardin, L. (1977). Análise de Conteúdo. Lisboa: Edições 70.

Bernardi, A. P. A., Queiroz, A. C. R. de, Lima, C. J. de, Sole, E. D., Shimozono, E., Paparelli, R. \& Prioste, S. V. (2000) Trabalho por telefone associado ao uso de terminal de computador (telework): estudo de caso. In L. I. Sznelwar \& L. N. Zidan (Orgs.), O trabalho humano com sistemas informatizados no setor de serviços. São Paulo: Plêiade.

Campos, M. M., Füllgraf, J. B. G. \& Wiggers, V. (2006). Qualidade na educação infantil: alguns resultados de pesquisas. Cadernos de Pesquisa, 36 (127), 87-128.

Campos, M. M., Rosemberg, F. \& Ferreira, M. I. (1995). Creches e pré-escolas no Brasil. São Paulo: Cortez.

Chaui, M. (1986). Conformismo e resistência: aspectos da cultura popular no Brasil. São Paulo: Brasiliense.

Crepaldi, R. (2002). A integração da rede de creches ao sistema municipal de ensino. Dissertação de Mestrado, Faculdade de Educação, Universidade de São Paulo, São Paulo.

Dejours, C. (1986). Por um novo conceito de saúde. Revista Brasileira de Saúde Ocupacional, 54, 7-11.

Gonçalves Filho, J. M. (1998). Humilhação social: um problema político em psicologia. Psicologia USP, 9 (2), 11-67.

Heller, A. (1972). O Cotidiano e a História. Rio de Janeiro: Paz e Terra.

Jardim, F. A. A., Otero, M. R., Silva, M. C. \& Dowbor, M. (2004). A Organização no local de trabalho: caminhos e desafios do cooperativismo. In L. Dowbor, O. Furtado, L. Trevisan \& H. Silva (Orgs.), Desafios do trabalho. Petrópolis: Vozes.

Lispector, C. (1994). A descoberta do mundo. Rio de Janeiro: Francisco Alves.

Marx, K. (1978). O Capital: crítica da economia política. São Paulo: Ciências Humanas.

Mendes, R. \& Dias, E. C. (1991). Da medicina do trabalho à saúde do trabalhador. Revista de Saúde Pública, 25 (5), 341-349.

Micarello, H. (2003). A formação de profissionais da educação infantil: em foco a relação teoria e prática. XXVI Reunião da ANPEd. 
Minayo, M. C. S. (1993). O desafio do conhecimento: pesquisa qualitativa em saúde. São Paulo: Hucitec.

Nascimento, M. E. P. (2001). Os profissionais da Educação Infantil e a nova Lei de Diretrizes e Bases da Educação Nacional. In A. L. G. Faria \& M. S. Palhares (Orgs.), Educação Infanti pós-LDB: rumos e desafios. São Paulo: Autores Associados.

Paro, V. H. (2003). Administração Escolar: introdução crítica (12ª ed.). São Paulo: Cortez.

Paro, V. H. (1993). A natureza do trabalho pedagógico. Revista da Faculdade de Educação, 19 (1), 103-109.

Paro, V. H. (1995). Por dentro da escola pública. São Paulo: Xamã.

Rocha, E. A. C., Silva Filho, J. J. \& Strenzel, G. R. (1999). O estado do conhecimento da Educação Infantil no Brasil (1983-1996).

Rocha, E. A. C. (1998). A pesquisa em Educação Infantil no Brasil: trajetória recente e perspectivas de consolidação de uma pedagogia. Tese de Doutorado, Faculdade de Educação, UNICAMP, Campinas.

Rosemberg, F., Campos, M. M. \& Pinto, R. P. (1985). Creches e pré-escolas. São Paulo: Nobel.

Rossetti-Ferreira, M. C, Mello, A. M., Vitoria, T., Gosuen, A. \& Chaguri, A. C. (Orgs.) (2005). Os fazeres na educação infantil (7ª ed.). São Paulo: Cortez.

Sato, L. (1995). A representação social do trabalho penoso. In M. J. P. Spink (Org.). O conhecimento no cotidiano: as representações sociais na perspectiva da psicologia social. São Paulo: Brasiliense.

Unesco (2003). Os serviços para a criança de 0 a 6 anos no Brasil: algumas considerações sobre o atendimento em creches e pré-escolas e sobre a articulação de políticas. Brasília: Unesco.

Weil, S. (1996). Carta a Albertine Thévenon 1934-1935. In Simone Weil: a condição operária e outros estudos sobre a opressão. Rio de Janeiro: Paz e Terra.

\section{Endereço para correspondência}

rpaparel@uol.com.br, thaisaurungo@uol.com.br, lu.na.g@hotmail.com, taniaverissimo@bol.com.br 